\title{
Preliminary results of land subsidence monitoring project in Konya Closed Basin between 2006-2009 by means of GNSS observations
}

\author{
A. Ustun ${ }^{1}$, E. Tusat ${ }^{2}$, and S. Yalvac ${ }^{1}$ \\ ${ }^{1}$ Selcuk University, Geomatics Eng. Dept., Kampus, Konya, 42031, Turkey \\ ${ }^{2}$ Selcuk University, Vocational High School of Cumra, Cumra, Konya, 42500, Turkey
}

Received: 22 July 2009 - Revised: 20 April 2010 - Accepted: 9 May 2010 - Published: 10 June 2010

\begin{abstract}
One of the potential dangers that might arise as a result of bringing excessive amounts of groundwater to the surface of the Earth is land subsidence. Such surface deformations - these velocities may vary from a few millimetres to a few metres per year - do the greatest damage to infrastructure facilities and buildings in residential units. Agricultural lands, in which excessive irrigation is performed, and densely populated cities are more likely to suffer from land subsidence. Konya Closed Basin (KCB), where a rapid groundwater withdrawal has been observed during the last $30-40$ years, is faced with such a threat. In this study, the possibility of the occurrence of land subsidence, related to groundwater withdrawal for the $\mathrm{KCB}$, is assessed and the geodetic studies conducted up to now, with the intention of identifying land subsidence, are introduced. The vertical displacements of between -12 and $-52 \mathrm{~mm} /$ year have been detected through GNSS observations collected on the 6-point test network. The land subsidence phenomenon has been developing in the areas where the groundwater is extensively used for irrigation and daily life. The results support the findings derived from the historical leveling records and point out the need of an extended study based on both GNSS and InSAR techniques for spatial and temporal mapping of land subsidence in the KCB.
\end{abstract}

\section{Introduction}

Humankind, since the beginning of its existence, has exploited nature in accordance with vital, social and economic needs and, in some cases, felt it necessary to change its natural structure. When the period covering the last two hundred years is considered, the natural appearance of the Earth has

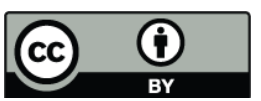

Correspondence to: A. Ustun (austun@ @elcuk.edu.tr) been changed by human activity in an ever increasing manner. The most typical example of this concerns engineering projects related to exploitation of water resources. Likewise, the rapid population rise and the accompanying urbanization, the expansion of farm lands and the industrialization requires fighting against nature. The pressure on limited natural resources, water above all, is increasing in time.

Another problem triggered by the extraction of mineral resources such as water, petrol, coal, etc., is land subsidence. Information concerning the location, causes and the spatial size of land subsidence across the world has been collected, thanks to a project initiated by the International Association of Hydrographic Sciences (IAHS) and UNESCO in 1969. According to the records kept in the unplanned database, more than 200 occurrences of land subsidence have been documented during the past 30 years (see http://isols.usgs.gov/). The only record in this database about Turkey relates to the mining activity in Zonguldak, the northwestern Turkey. It has been observed that a large majority of the records are connected with the withdrawal of groundwaters. Places where such phenomena are most frequent are metropolitan areas and farmlands where groundwater is used extensively. Some examples of such places in which subsidences have been observed are given by Abidin et al. (2001) in Jakarta, Lopez-Quiroz et al. (2009) in Mexico City, Chai et al. (2004) in Shanghai, Ishii et al. (1976) in Tokyo. These are examples in metropolitan areas. Other examples in sedimentary (coastal or river) basins are sampled by Mashhad Valley, Iran (Motagh et al., 2007), Po Plain, Italy (Carminati and Martinelli, 2002), San Joaquin Valley, California (Deverel and Rojstaczer, 1996), Shiroishi of Saga plain, Japan (Don et al., 2006). The subsiding areas listed here are all consequences of the changes of the sub-surface water levels due to groundwater abstraction.

If it is handled within the framework of the problems mentioned above, Konya Closed Basin (KCB) is known as the basin where groundwater is intensively exploited in

Published by Copernicus Publications on behalf of the European Geosciences Union. 


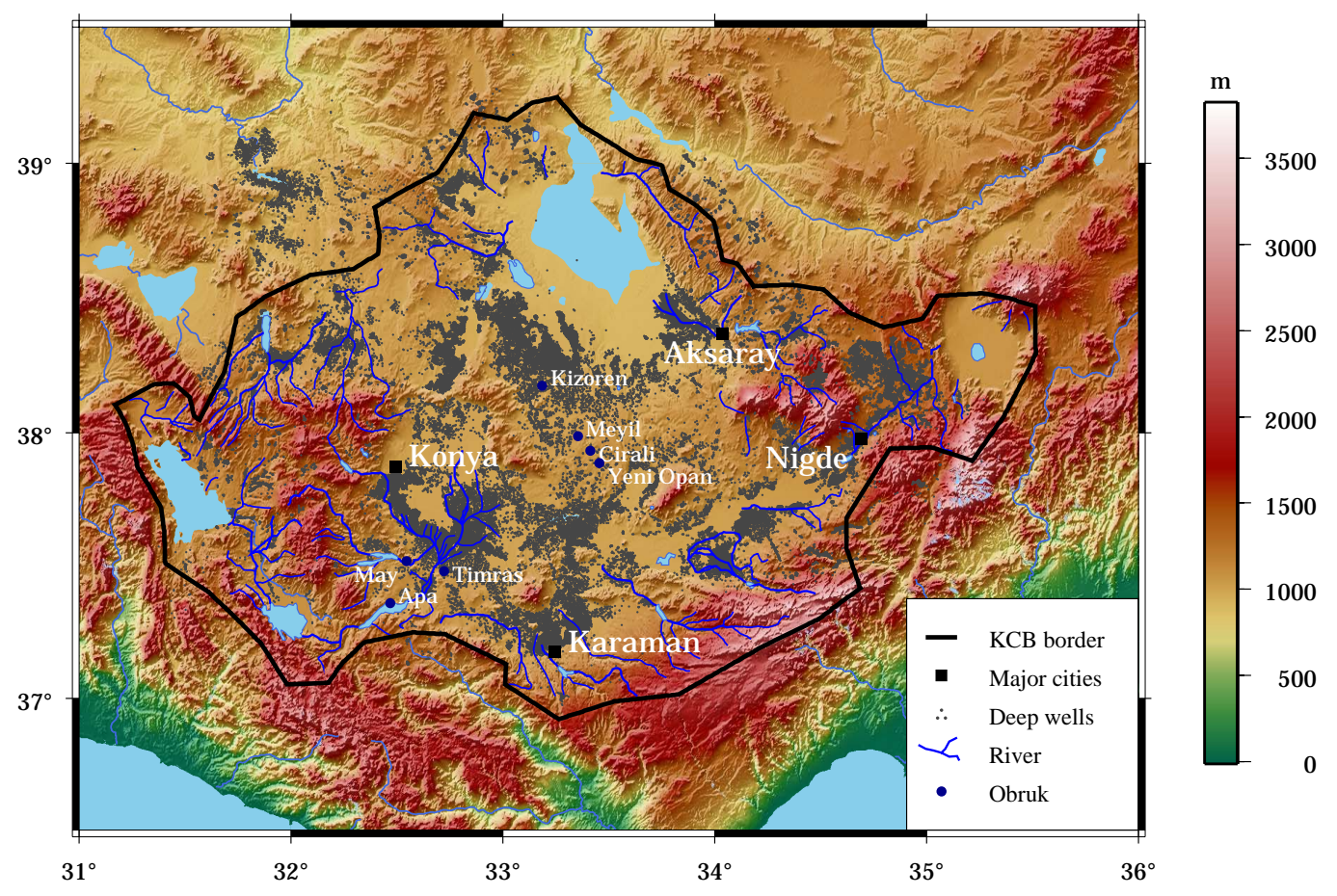

Fig. 1. Konya Closed Basin and distribution of deep wells used for groundwater abstraction.

Turkey. It is an endorheic drainage basin covering a total of $55000 \mathrm{~km}^{2}$. In addition to the fact that the basin is a highly productive agricultural area, the rapid rise of population in urban centres, notably in Konya, the increasing expansion of the industrial production and other reasons have laid the basis for a more extensive use of the groundwater due to insufficient surface water resources. The water level observations, conducted during the last 30-40 years in the wells run by the Directorate of State Hydraulic Works, revealed water withdrawals that reached almost $1 \mathrm{~m} /$ year (Dogdu et al., 2007; Ustun et al., 2007a). Besides, the data indicate that the withdrawal is not linear in time but rather it intensifies in an ever increasing manner.

When all such information, examples and other probable scenarios regarding climate in the future are considered, the possibility of an irreversible decrease in the water resources of the KCB and the other accompanying problems increases. As evidence of such problems, the leveling records which were carried out in different time periods from 1970s to 2000s show that there are height changes reaching up to $50 \mathrm{~cm}$ at the first and second order leveling benchmarks, especially in the city center of Konya.

In this study, the possibility of the occurrence of land deformation related to groundwater withdrawal in the KCB is assessed and available geodetic methods for identifying land deformation are introduced. Within this scope, a GNSS deformation network, established in 2006, and the point deformation values, obtained from the campaign measurements on this network up until now, will be discussed.

\section{Konya Closed Basin and withdrawal of groundwater}

With a population of almost 5 million people, Konya Closed Basin is located in the Central Anatolia Region. It was formed as a result of the rise of an old river bed in central Anatolia due to air movements. At the end of the Ice Age, melting glaciers resulted in seas rising and floods that swept away the whole Anatolia causing large quantities of residue to accumulate in the area. Today, it looks like a plain with heights varying between 900 and $1050 \mathrm{~m}$. This plain covers most of the basin and constitutes the major part of the Central Anatolian Plateau. Its soil is generally alluvial and saline as a consequence of insufficient drainage. The plain is covered with limestone, which forms the upper catchment basin, and volcanic mountainous areas. These same mountains prevent surface waters from draining to the sea and effectively forms Turkey's largest closed basin (Fig. 1).

The water sources of the basin are predominantly the rivers in the west and the south and the groundwater units feeding from the Taurus mountains. Despite its insufficient surface water resources, apart from Lake Beysehir, low precipitation and high evaporation, the KCB possesses a great groundwater potential by virtue of its hydrogeological composition. Neogene lacustrine limestone makes up most of the area's aquifer composition. Though the thickness of the aquifer deposits vary from region to region, it reaches $250 \mathrm{~m}$ in the Konya plain. Further information concerning the hydrogeological composition can be obtained from e.g. Tuzcu et al. (1971); Agacik et al. (1975); Bayari et al. (2009). 

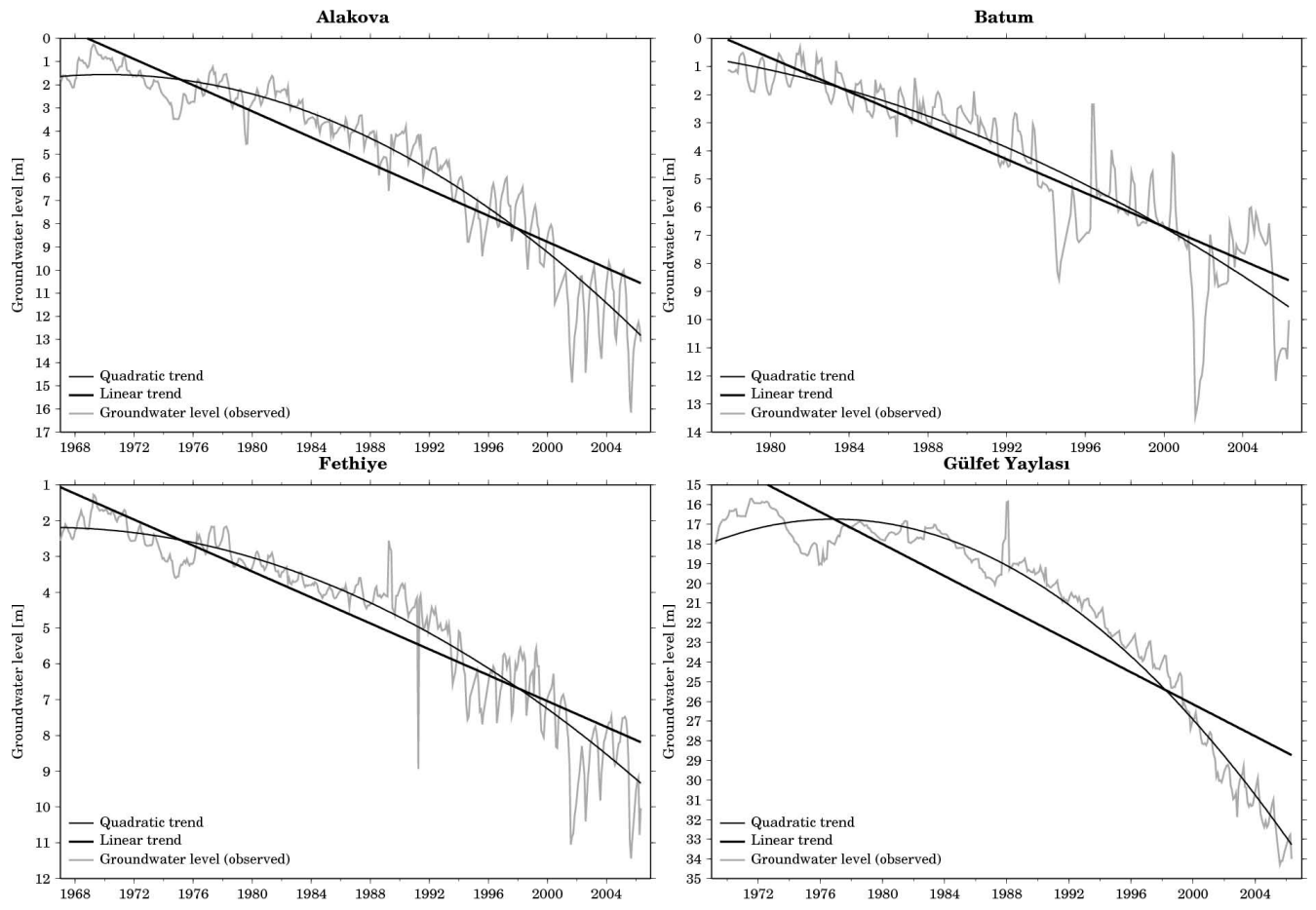

Fig. 2. Observations of water levels (monthly) for selected wells in KCB and their linear and quadratic trends.

Annual precipitation in the whole basin is almost half that of the average value in Turkey, which is $300-350 \mathrm{~mm} / \mathrm{year}$. With the human population increase, the overuse of water for agricultural and industrial purposes and other factors are to be considered, making the given figures insufficient to support the water supply. The unconscious and excessive exploitation of the groundwater in recent years has endangered sustainability of this resource. An inventory study on the status of groundwater usage within Konya Closed Basin displays the quantity of deep pumping wells that draw water from deep underground sources. Figure 1 shows the distribution of deep wells that provide the groundwater for both irrigation and water supply for the basin. According to the official records, $70 \%$ of nearly 100000 deep wells are illegal (Iscioglu, 2008). It is expected that a severe degradation in the reserves of groundwater due to high evaporation rates and overexploitation of aquifers in contrast to low precipitation input.

The groundwater level measurements of 24 wells, operated by the 4th Regional Directorate of State Hydraulic Works, clearly demonstrate the decrease in the water levels. In several stations, the elevation of the water level has been measured for 30-40 years. Figure 2 shows some examples of the time series of monthly water levels with the linear and quadratic trends. A significant decrease was observed in all of the wells. The average linear trend is $0.77 \mathrm{~m} /$ year. Moreover, as can be seen in Fig. 2, the decrease is not linear in most of the wells; the speed as well as the amplitude of seasonal effects on water levels have increased in time. Dogdu et al. (2007) demonstrate that the values of precipitation in the KCB, since the beginning of the 1980s, have an influence on the decline of groundwater levels.

\section{Land subsidence in $\mathrm{KCB}$ and its monitoring by geodetic methods}

\subsection{Leveling results of two periods, 1970-80s and 2005}

The signs of local surface deformations in the KCB have been sought firstly in the precise leveling data. Some leveling benchmarks (see Fig. 3), which are part of the Turkish National Vertical Control Network (TNVCN), had been observed in two different periods, 1973-1984 and 2005. The first period measurements were performed by the General Command of Mapping in order to re-establish the TNVCN. The latter was conducted by the civil government for the construction of a drainage system for rain water in Konya city centre. For this campaign, the leveling heights were estimated from the well-known least squares method by fixing four stations (Anonymous, 2005). The computations were made by the General Command Mapping of Turkey. Since the goal of the study was the densification of the existing leveling network and the production of new height values, the land subsidence effect on the leveling benchmarks was not investigated. According to the report, the consistency of height differences (e.g. leveling measurements) between 


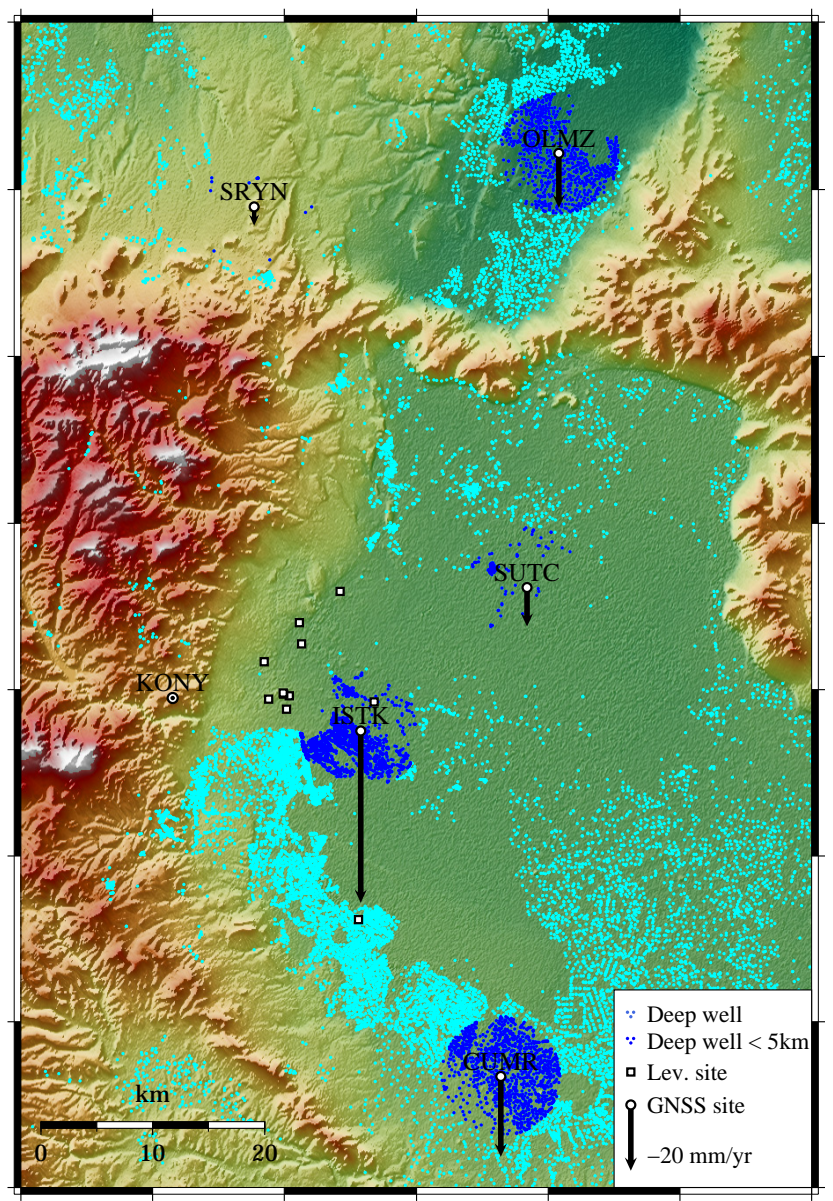

Fig. 3. Vertical displacement rates (referred to KONY). Blue dots show deep wells, dark blue dots represent the deep wells within a circle centred at GNSS stations with a 5-km radius.

adjacent benchmarks at different periods was taken into account in the selection of reference stations. From the comparison of height values, it has been observed that the heights at 8 points have changed from $-521 \mathrm{~mm}$ to $303 \mathrm{~mm}$ during the time span of 20-30 years (Table 1).

The magnitude of the height changes depends upon the selection of data in the adjustment computation. As mentioned above, the fact that the second period measurements were done without considering possible local deformations made, it was difficult to identify absolute subsidence values at the benchmarks. It has been understood that all points, including the reference stations, are located on the subsiding area. Although both the network design and the datum selection procedure are problematic from the view of defining the actual deformation magnitudes, the relative height changes clarify that Konya city centre and the surrounding area are exposed to land subsidence.
Table 1. Comparison of the heights from precise leveling in different time periods, 1973-1984 and 2005 (Anonymous, 2005).

\begin{tabular}{cccccc}
\hline Station & Height & $\begin{array}{c}\text { Meas. } \\
\text { Year }\end{array}$ & $\begin{array}{c}\text { Height } \\
\text { at 2005 } \\
(\mathrm{m})\end{array}$ & $\begin{array}{c}\text { Height } \\
\text { diff. } \\
(\mathrm{mm})\end{array}$ & $\begin{array}{c}\text { Slope } \\
\mathrm{mm} / \text { year }\end{array}$ \\
\hline 1001 & 1006.464 & 1984 & 1006.464 & 0 & 0 \\
1002 & 1001.811 & 1984 & 1001.811 & 0 & 0 \\
1003 & 1002.683 & 1982 & 1002.683 & 0 & 0 \\
1004 & 1013.950 & 1973 & 1013.950 & 0 & 0 \\
1 & 1007.828 & 1974 & 1008.122 & 294 & 9 \\
2 & 1021.684 & 1974 & 1021.287 & -397 & -13 \\
3 & 1014.544 & 1975 & 1014.339 & -205 & -7 \\
4 & 1017.833 & 1982 & 1017.312 & -521 & -23 \\
5 & 1016.373 & 1975 & 1016.161 & -212 & -7 \\
6 & 1012.250 & 1975 & 1012.172 & -78 & -3 \\
7 & 1016.150 & 1973 & 1016.453 & 303 & 9 \\
8 & 1018.337 & 1975 & 1018.042 & -295 & -10 \\
\hline
\end{tabular}

\subsection{Land Subsidence monitoring network and GNSS data processing}

Having exhibited the relative displacements on the first order leveling benchmarks, a new monitoring in the Konya Closed Basin due to groundwater withdrawal began towards the end of 2005 by proposing the design of a GNSS test network (Ustun et al., 2007b). By reason the KCB extends over $7 \%$ of Turkey, the stations of the test network were selected in a limited area encompassing the municipal district of Konya. As seen in Fig. 3, it consists of six geodetic monuments used to monitor relative displacements in terms of horizontal and vertical components by GNSS positioning. Unlike the leveling network, the GNSS network was designed to consider the ground stability and the use of groundwater in the studied area. When configuring the subsidence network, KONY station was chosen on stable ground. It is outside the influence zone of groundwater extraction. The other stations are in relatively flat parts of the basin where agricultural activities are concentrated. The lengths of the total 15 baselines vary from 15 to $70 \mathrm{~km}$.

The campaign measurements on the network began in March 2006 and so far (January 2010), GNSS data of six periods has been collected. Each campaign was held in two sessions on repeated days so that ellipsoidal height precision would remain below $1 \mathrm{~cm}$. The GNSS code and carrier phase observation data in both frequencies were recorded for $8-10 \mathrm{~h}$ during each session. The observations were made simultaneously at all points of the network. For this purpose, 6 Trimble 5700 receivers and Zephyr geodetic antennas in the first three campaigns and 6 Topcon Hiper Pro receivers in the other campaigns were used. While the Trimble 5700 receivers are capable for GPS observations only, Topcon receivers can track both GPS and GLONASS satellites seamlessly. 
Table 2. Position changes and velocities and their uncertainties at GNSS stations (referred to KONY).

\begin{tabular}{|c|c|c|c|c|c|c|}
\hline \multirow{2}{*}{$\begin{array}{l}\text { Station } \\
\text { name }\end{array}$} & \multicolumn{3}{|c|}{ Position changes at 3.6 years } & \multicolumn{3}{|c|}{ Velocity } \\
\hline & $\begin{array}{c}n \\
\mathrm{~mm}\end{array}$ & $\begin{array}{c}e \\
\mathrm{~mm}\end{array}$ & $\begin{array}{c}u \\
\mathrm{~mm}\end{array}$ & $\begin{array}{c}v_{\mathrm{n}} \\
\mathrm{mm} / \mathrm{yr}\end{array}$ & $\begin{array}{c}v_{\mathrm{e}} \\
\mathrm{mm} / \mathrm{yr}\end{array}$ & $\begin{array}{c}v_{\mathrm{u}} \\
\mathrm{mm} / \mathrm{yr}\end{array}$ \\
\hline OLMZ & $-9.8 \pm 2.8$ & $4.3 \pm 2.5$ & $-74.0 \pm 7.9$ & $-1.6 \pm 0.6$ & $0.7 \pm 0.7$ & $-16.5 \pm 3.7$ \\
\hline SUTC & $-4.0 \pm 1.7$ & $9.1 \pm 2.4$ & $-49.8 \pm 7.5$ & $0.5 \pm 0.6$ & $1.7 \pm 0.7$ & $-11.8 \pm 3.3$ \\
\hline CUMR & $-1.4 \pm 2.2$ & $1.9 \pm 2.2$ & $-84.2 \pm 7.0$ & $1.1 \pm 0.6$ & $0.2 \pm 0.7$ & $-24.3 \pm 3.1$ \\
\hline ISTK & $-18.9 \pm 1.8$ & $-18.5 \pm 2.1$ & $-172.6 \pm 8.2$ & $-2.8 \pm 0.6$ & $-5.4 \pm 0.7$ & $-52.2 \pm 3.5$ \\
\hline SRYN & $-5.6 \pm 2.6$ & $4.8 \pm 1.9$ & $-22.5 \pm 7.4$ & $-0.8 \pm 0.6$ & $1.0 \pm 0.7$ & $-5.8 \pm 3.4$ \\
\hline
\end{tabular}

The GNSS measurements were processed on a daily basis using GAMIT (Release 10.33 Herring et al., 2008). The GAMIT solution for each session produces minimally constrained intermediate results of station coordinates, orbital and Earth orientation parameters associated with their covariance matrices. Each session was evaluated separately (12 in total) and then the results were combined to obtain average positions and velocities for station coordinates using global Kalman (GLOBK) filter (ibid.). In addition to the existing dataset of the subsidence network, several IGS (International GNSS Service) sites, which work simultaneously for all the campaigns, were included to provide a reference frame definition based on the International Terrestrial Reference Frame 2005 (ITRF2005). The mean sigma values (standard deviations) of the adjusted station positions are 2.2, 2.2 , and $7.6 \mathrm{~mm}$ in terms of local coordinate components, north, east and up, respectively. The last value determines at what level the vertical coordinate change between two periods can be interpreted as deformation. According to this, positional changes that exceed $3 \sigma$ (approximately $\pm 2 \mathrm{~cm}$ ) in the vertical direction, should be interpreted as significant in this GNSS network.

The reference frame for local deformation analysis was fixed by applying constraints on the coordinates and velocities of KONY. Table 2 gives the estimated displacements during 3.6 years and the velocity values and their uncertainties at GNSS sites. The results show that all stations subside with respect to KONY. To be able to understand and analyse the relationship between the subsidence rates and groundwater usage, the density of deep wells within a $5-\mathrm{km}$ radius from each GNSS site was determined. The subsidence values are highly correlated with the use of groundwater (see Figs. 3 and 4). The Pearson correlation coefficient between them was found to be -0.908 for 5 sites. As expected, SRYN moved slowly in comparison with the others, because it is outside of the subsidence area. ISTK and CUMR are located in densely populated and irrigated areas of the KCB, respectively. For these two points, the calculated vertical land surface changes from the six-period measurements between March 2006 and October 2009 are $-84 \mathrm{~mm}$ (CUMR) and $-173 \mathrm{~mm}$ (ISTK).

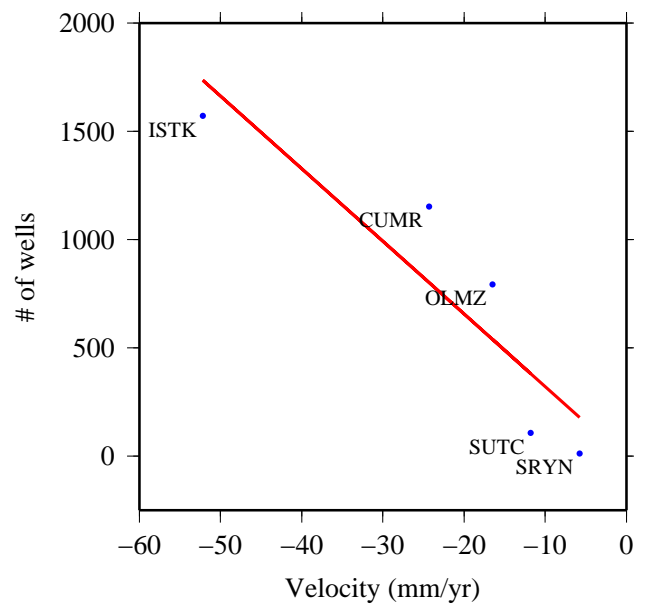

Fig. 4. Correlation between the land subsidence rates and the use of groundwater around the GNSS sites.

\section{Discussion}

A comparison between the subsidence velocities obtained by GNSS and those from the historical leveling measurements is not possible because their point distributions do not overlap. Also, the leveling network covers only Konya city centre and the selected reference stations are located in the subsidence zone. This makes it impossible to carry out a direct comparison. At this stage, it can be said that only both of the geodetic methods revealed the presence of a land subsidence effect changing spatially in Konya Closed Basin.

For GNSS networks having long baselines $(>10 \mathrm{~km})$ and considerable height differences between points, it is difficult to hold uncertainties below $1 \mathrm{~cm}$ for the height component in GNSS positioning which takes a time span of less than half a day due to atmospheric gradients, multipath effects, etc. Under these conditions, the observation strategy and processing are successful in view of identifying displacements in the vertical direction with an accuracy level of 7-8 $\mathrm{mm}$. It can be mentioned that the results obtained from the GNSS measurements reveal a realistic picture of what the magnitude of land subsidence varies in the KCB. 
In this study, it is conjectured that the detected surface subsidences are mainly caused by excessive exploitation of groundwater. In order to see the effect of the groundwater decline on the rate of subsidence at the GNSS sites, the amount of deep wells to exploit groundwater in the basin has been utilized. The number of wells within $5 \mathrm{~km}$ of a site-centred gives a satisfactory idea about the usage of groundwater. Thus, the rates of subsidence at 5 GNSS are highly correlated with the stress on the groundwater resources created by the legal and illegal deep wells. To make this finding more concrete, there has been a need for more quantitative data on the behaviour of the water table (i.e. water level observations simultaneously with GNSS data) and ground characteristics based on geotechnical analysis in the vicinity of GNSS sites. For the existing GNSS network with an increased number of stations, such a study is considered.

The GNSS data over the study area was collected in the time span from the beginning of 2006 to the end of 2009. Because of the factors such as spreading the GNSS network over a wide area, the restrictions on historical leveling records, and founding problems, monitoring of land subsidence in Konya Closed Basin has been limited to GNSS observations with several stations only. When considering the size of the basin, SAR interferometry (see e.g. Massonnet and Feigl, 1998) as a geodetic technique seems to be an efficient and valid method for spatial and temporal monitoring of these occurrences. The further work planned consists of validating the information provided by the GNSS measurements and large-scale mapping of surface deformations using the InSAR technique.

\section{Conclusions}

Land subsidence is only one of the problems that may be caused by overuse of groundwater. However, the real threat which land subsidence may bring along is the material damage it will do to the infrastructural systems. When land subsidence events come together with other environmental risks, it may lead to losses of life and property. One way of preventing possible problems is monitoring places through geodetic methods where land subsidence may occur. Areas where groundwater is rapidly withdrawn are always faced with the threat of land subsidence.

In this study, the geodetic deformation network, which was established to determine vertical deformations caused by the withdrawal of groundwaters in the Konya Closed Basin, is introduced, and the results of the GNSS measurements performed on this network are revealed. The GNSS observations were collected in six periods between 2006 and 2009 on the 6-point GNSS test network. The vertical position changes which were determined by fixing a one point vary in the range of -22 to $-173 \mathrm{~mm}$. When these values are converted into a standard value versus time, subsidence rates reaching up to $1-5 \mathrm{~cm}$ annually are obtained. Vertical positioning ac- curacy of $7.6 \mathrm{~mm}$, calculated from the processing of all session data, points out that the subsidences estimated at GNSS sites are quite significant. Furthermore, it has been observed that the magnitude of land subsidence effect in the KCB has a high correlation of $-90 \%$ with the usage of groundwater around GNSS site.

The other geodetic methods used in monitoring the land subsidence, apart from GNSS, are precise leveling and InSAR techniques. Although historical data have been very useful for describing surface deformation in a specific area, it is not easy to find them. The leveling records in 19701980 s and 2000s for a small part of the KCB have played an important role in distinguishing land subsidence. However, conducting measurements of the leveling network established in large areas, such as the KCB, is not economical and requires considerable manpower and time. Similar considerations also exist for GNSS networks. Thus, there is a need for an appropriately designed GNSS network in such applications. The InSAR technique is very useful because surface deformations are determined on a spatial scale with millions of pixels.

The historical leveling data and the land subsidence test network, designed for this study, have provided evidence for the existence of land subsidence in the KCB. Results of the application cover a limited section of the basin. In order to make an evaluation regarding the whole of the basin, the established network is going to be expanded, i.e. new points will be added to the network in the additional study. Moreover, in contrast to the limited facilities of GNSS technique, the InSAR technique will be used for mapping and monitoring of the land subsidence in the $\mathrm{KCB}$.

Acknowledgements. This research was supported by the Coordinatorship of Selcuk University Scientific Research Projects. The authors would like to thank A. Kilinc for providing the GNSS receivers for data collection and students for joining the field studies. The groundwater use and water level analysis were done using the data supplied from 4th Regional Directorate of State Hydraulic Works. C. Can afforded the opportunity to reach the leveling records. Lastly, we also thank anonymous reviewers for their valuable comments and suggestions that greatly improved the manuscript.

Edited by: F. Guzzetti

Reviewed by: three anonymous referees

\section{References}

Abidin, H. Z., Djaja, R., Darmawan, D., Hadi, S., Akbar, A., Rajiyowiryono, H., Sudibyo, Y., Meilano, I., Kasuma, M. A., Kahar, J., and Subarya, C.: Land subsidence of Jakarta (Indonesia) and its geodetic monitoring system, Nat. Hazards, 23, 365-387, 2001.

Agacik, G., Gulenbay, G., Orhon, E., Sozen, M., Tezel, H., and Giritlioglu, T.: Hydrogeological investigation report of KonyaCumra and Karapinar Plains, State Hydraulic Works, Ankara, 
Tech. rep., 1975 (in Turkish).

Anonymous: The rainwater drainage project of Konya, General Command of Mapping, Ankara, Tech. Rep., 2005 (in Turkish).

Bayari, C. S., Ozyurt, N. N., and Kilani, S.: Radiocarbon age distribution of groundwater in the Konya Closed Basin, central Anatolia, Turkey, Hydrogeol. J., 17, 347-365, 2009.

Carminati, E. and Martinelli, G.: Subsidence rates in the Po Plain, northern Italy: the relative impact of natural and anthropogenic causation, Eng. Geol., 66, 241-255, 2002.

Chai, J. C., Shen, S. L., Zhu, H. H., and Zhang, X. L.: Land subsidence due to groundwater drawdown in Shanghai, Geotechnique, 54, 143-147, 2004.

Deverel, S. J. and Rojstaczer, S.: Subsidence of agricultural lands in the Sacramento-San Joaquin delta, California: role of aqueous and gaseous carbon fluxes, Water Resour. Res., 32, 2359-2367, 1996.

Dogdu, M. S., Toklu, M. M., and Sagnak, C.: Analysis of precipitation and groundwater levels in Konya Closed Basin, in: Congress on Climate Change in Turkey, Istanbul, edited by: Oztopal, A. and Sen, Z., 394-401, 11-13 April 2007 (in Turkish).

Don, N. C., Hang, N. T. M., Araki, H., Yamanishi, H., and Koga, K.: Groundwater resources management under environmental constraints in Shiroishi of Saga plain, Japan, Environ. Geol., 49, 601-609, 2006.

Herring, T. A., King, R. W., and McClusky, S. C.: Introduction to GAMIT/GLOBK: Release 10.3, 2008.

Iscioglu, A.: An overview of groundwater use and allocation in Konya Closed Basin, in: Conference on groundwater and drought in Konya Closed Basin, Konya, Ipek Ofset, 135-142, 11-12 September 2008 (in Turkish).
Ishii, M., Kuramochi, F., and Endo, T.: Recent tendencies of the land subsidence in Tokyo, in: IAHS Proceedings of the Anaheim Symposium, 25-34, 1976.

Lopez-Quiroz, P., Doin, M.-P., Tupin, F., Briole, P., and Nicolas, J.-M.: Time series analysis of Mexico City subsidence constrained by radar interferometry, J. Appl. Geophys., 69(1), 1-15, doi:10.1016/j.jappgeo.2009.02.006, 2009.

Massonnet, D. and Feigl, K.: Radar interferometry and its application to changes in the Earth's surface, Rev. Geophys., 36, 441500, 1998.

Motagh, M., Djamour, Y., Walter, T. R., Wetzel, H. U., Zschau, J., and Arabi, S.: Land subsidence in Mashhad Valley, northest Iran: results from InSAR, levelling and GPS, Geophys. J. Int., 168, 518-526, 2007.

Tuzcu, G., Agacik, G., Giritlioglu, T., and Sozen, M.: Hydrogeological investigation report of Cihanbeyli, Yeniceoba and Kulu Plains, State Hydraulic Works, Ankara, Tech. rep., 1971 (in Turkish)

Ustun, A., Abbak, R. A., Yigit, C. O., and Tusat, E.: Trend and Correlation Analysis of Groundwater Levels in Konya Closed Basin, in: IUGG General Assembly, Earth: Our Changing Planet, Perugia, 2-13 July 2007a.

Ustun, A., Tusat, E., and Abbak, R. A.: Groundwater withdrawal in Konya Closed Basin and monitoring of its possible consequences by geodetic techniques, in: 3rd Symposium on Engineering Surveys, 24-26 October 2006, Konya, Hermes Tanitim Ofset Ltd. Şti., Ankara, 52-61, 2007b (in Turkish). 